\title{
Correlation between Clinical Pathologic Factors and Activity of 5-FU-Metabolizing Enzymes in Colorectal Cancer
}

\author{
Takeshi Yamada ${ }^{1,2}$, Noritake Tanaka ${ }^{1,2}$, Kimiyoshi Yokoi ${ }^{1,2}$, Tomoko Seya ${ }^{1,2}$, \\ Yoshikazu Kanazawa ${ }^{1,2}$, Michihiro Koizumi ${ }^{1,2}$, Yoshiharu Ohaki ${ }^{3}$ and Takashi Tajiri ${ }^{1}$ \\ ${ }^{1}$ Surgery for Organ Function and Biological Regulation, Graduate School of Medicine, Nippon Medical School \\ ${ }^{2}$ Department of Surgery, Nippon Medical School, Chiba Hokusou Hospital \\ ${ }^{3}$ Department of Pathology, Nippon Medical School, Chiba Hokusou Hospital
}

\begin{abstract}
Introduction: Orotate phosphoribosyl transferase (OPRT), dihydropyrimidine dehydrogenase (DPD), and thymidylate synthase (TS) are initial key enzymes in the 5fluorouracil (5-FU) metabolic pathway. The expression levels and activities of these three enzymes play important roles in the response of cancer patients to 5-FU-based chemotherapy.

Purpose: The purpose of this study was to investigate the relationship between the activities of 5-FU metabolic enzymes and clinicopathologic factors in colorectal cancer.

Methods: We measured the activities of OPRT, DPD, and TS in colorectal cancer tissues. We also investigated the correlations between the activities of these three enzymes and clinicopathologic factors (histological type, depth of tumor invasion, extent of lymph node metastasis, Dukes' stage, lymphatic invasion, and vascular invasion). We examined 100 patients with surgically resected colorectal cancer.

Results: Poorly differentiated adenocarcinoma showed significantly higher DPD activities than did moderately differentiated or well-differentiated adenocarcinoma. In patients with lymph-node metastasis, OPRT activity was significantly lower than in patients without lymphnode metastasis. No significant relation was found between TS activity and histological type, depth of tumor invasion, extent of lymph node metastasis, Dukes' stage, lymphatic invasion, or vascular invasion.

Conclusion: The response to 5-FU may be poor in patients with lymph-node metastasis, because of low OPRT activity, and in patients with poorly differentiated adenocarcinoma, because of high DPD activity.
\end{abstract}

(J Nippon Med Sch 2008; 75: 23-27)

Key words: orotate phosphoribosyl transferase, dihydropyrimidine dehydrogenase, thymidylate synthase, colon cancer

Correspondence to Takeshi Yamada, Department of Surgery, Nippon Medical School, Chiba Hokusou Hospital, 1715 Kamagari, Inba-mura, Inba-gun, Chiba 270-1694, Japan

E-mail: y-tak@nms.ac.jp

Journal Website (http://www.nms.ac.jp/jnms/) 
T. Yamada, et al

Table 1 Patient characteristics

\begin{tabular}{lll}
\hline No. of patients & & 100 \\
\hline Age & & $67.5(38 \sim 90)$ \\
Gender & male/female & $67 / 33$ \\
location & $\mathrm{C} / \mathrm{A} / \mathrm{T} / \mathrm{D} / \mathrm{S} / \mathrm{R}$ & $6 / 20 / 7 / 4 / 19 / 44$ \\
Classification of tumor & $\mathrm{Well} / \mathrm{mod} / \mathrm{por} / \mathrm{muc}$ & $41 / 48 / 9 / 2$ \\
Depth of tumor invasion & $\mathrm{T} 2 / \mathrm{T} 3 / \mathrm{T} 4$ & $11 / 83 / 6$ \\
Lymph node metastasis & positive/negative & $39 / 61$ \\
Duke's stage & $\mathrm{B} / \mathrm{C} / \mathrm{D}$ & $36 / 40 / 23$ \\
Lyphatic invasion & $\mathrm{Ly}(-) / \mathrm{Ly}(+)$ & $9 / 91$ \\
Vascular invasion & $\mathrm{V}(-) / \mathrm{V}(+)$ & $13 / 87$ \\
\hline well: well-differentiated & adenocarcinoma, mod: moderate differentiated \\
adenocarcinoma, por: poorly differentiated adenocarcinoma, muc: mucinous \\
adenocarcinoma
\end{tabular}

\section{Introduction}

Chemotherapy for colorectal cancer has progressed in recent years, and the prognosis of such cancer has improved. However, many patients show a poor response to anticancer agents and have severe adverse toxic effects. Molecular profiling of tumors may identify patients who are more likely to benefit from chemotherapy. Such profiling would enable clinicians to tailor treatment to each patient and tumor profile. Although a limited number of predictive markers have been identified, they may improve the response rate to chemotherapy.

5-Fluorouracil (5-FU) is one of the drugs most often used against colorectal cancer ${ }^{1}$. If we can predict the effect of $5-\mathrm{FU}$ before administration, patients can receive considerable benefit. Thymidylate synthase (TS), a target enzyme of 5FU, affects 5-FU sensitivity². A number of studies have demonstrated that patients with a low tumoral TS expression level have higher response rates to 5FU than do patients with tumors having a high TS expression level ${ }^{3.4}$. It has also been shown that dihydropyrimidine dehydrogenase (DPD), a ratelimiting enzyme for the degradation of 5 -FU, determines 5-FU sensitivity ${ }^{5,6}$. Furthermore it has been shown that orotate phosphoribosyl transferase (OPRT), an enzyme in the main pathway of 5-FU phosphorylation, also determines $5-\mathrm{FU}$ sensitivity ${ }^{7}$. These three enzymes may be strong predictive markers of 5-FU sensitivity.

If possible, it is desirable to measure the activities of these three enzymes or carry out a chemosensitivity test before administering 5-FU. However, it is impossible, as standard treatment, to measure the enzymatic activities or carry out a chemosensitivity test. Therefore, if we can predict the activities of these three enzymes on the basis of clinicopathologic factors, patients can receive a considerable benefit.

In this study, we measured the activities of OPRT, DPD, and TS in 100 patients with colorectal cancer and evaluated their relationships with clinicopathological factors.

\section{Materials and Methods}

Surgical specimens were obtained from patients 100 colorectal cancer, comprising 67 men and 33 women aged 38 to 90 years (Table 1). The specimens were frozen at $-80^{\circ} \mathrm{C}$ until the OPRT, DPD and TS activities were assayed. Written informed consent was obtained from all patients, and the study was approved by the ethics committee of our university hospital.

\section{Measurement of OPRT Activity}

A tissue sample (300 mg) was obtained from the resected tumor. The sample was immediately frozen and stored at $-80^{\circ} \mathrm{C}$ until the assay of OPRT activity. OPRT activity was determined with a 5-FU phosphorylation assay, as previously described ${ }^{8}$. The reaction rate was determined from the quantity of 5fluorouridine monophosphate (FUMP) produced through 5-FU phosphorylation by phosphoribosyl 


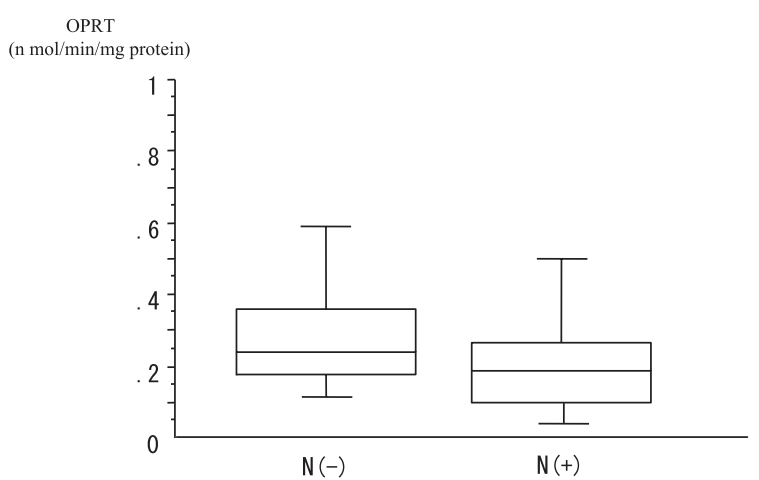

Fig. 1 OPRT and lymph node metastasis The OPRT activity was lower in cases of lymph node metastasis than in cases of no lymph node metastasis. The upper and lower limits of the boxes, and the lines across the boxes, indicate the $75^{\text {th }}$ and $25^{\text {th }}$ percentiles and medians, respectively.

pyrophosphate (PRPP), and OPRT activity per milligram of protein was calculated.

\section{Measurement of DPD Activity}

A tissue sample $(300 \mathrm{mg})$ was taken from the resected tumor. The sample was immediately frozen and stored $\left(-80^{\circ} \mathrm{C}\right)$ until the assay of DPD activity by radioassay. DPD activity was calculated by measuring the total production of metabolites of $\left[{ }^{[4} \mathrm{C}\right]-5-\mathrm{FU}$, which was added to the homogenized tissue samples, i.e., dihydrofluorouracil (DHFU), 2fluoro-b-ureidopropionate (F-b-UPA) and a-fluoro-balanine (F-b-Ala). 5-FU and the metabolites were separated by the thin-layer chromatography?

\section{Measurement of TS Activity}

A tissue sample $(300 \mathrm{mg}$ ) was taken from the resected tumor, and it was immediately frozen $\left(-80^{\circ} \mathrm{C}\right)$. TS (TS-free) activity was measured with a 5 fluorodeoxyuridine monophosphate (FdUMP) ligandbinding assay ${ }^{10}$.

\section{Statistical Analysis}

The Mann-Whitney U-test was used to compare the means between the groups. P-values less than 0.05 were considered to indicate statistical significance.

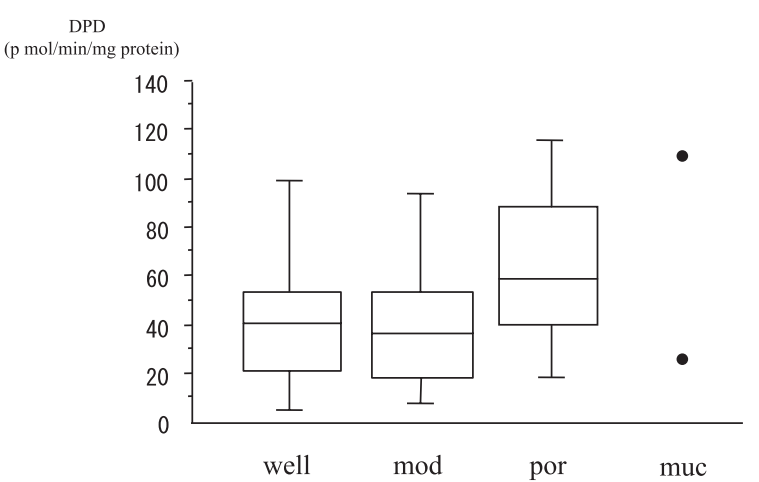

Fig. 2 DPD and Pathological type

Poorly differentiated adenocarcinomas showed a significantly higher DPD activity than moderately differentiated or well-differentiated adenocarcinomas. The upper and lower limits of the boxes, and the lines across the boxes, indicate the $75^{\text {th }}$ and $25^{\text {th }}$ percentiles and medians, respectively.

\section{Results}

No significant correlation was found between OPRT activity and histological type, depth of tumor, or Dukes' stage. However, the OPRT activity was lower in cases of lymph node metastasis than in cases of no lymph node metastasis (Fig. 1).

No significant correlation was found between DPD activity, depth of tumor or Dukes' stage. Poorly differentiated adenocarcinoma and mucinous adenocarcinoma showed a significantly higher DPD activity than did moderately differentiated or welldifferentiated adenocarcinoma (Fig. 2). DPD activity tended to be higher in cases with lymph-node metastasis than in cases without lymph-node metastasis; however, the difference was not significant.

No significant relationship was found between TS activity and histological type, lymph node metastasis, depth of tumor, Dukes stage, vascular invasion, or lymphatic invasion (Table 2).

\section{Discussion}

5-FU is the most widely used anticancer drug for colon cancer, and its efficacy varies with the activities of metabolic enzymes in cancer tissues ${ }^{3-7}$. Following uptake into cells, 5-FU is metabolized into 
T. Yamada, et al

Table 2 Enzyme activity assay results

\begin{tabular}{|c|c|c|c|c|c|c|c|}
\hline \multirow[b]{2}{*}{ location } & \multirow[b]{2}{*}{$\begin{array}{l}\text { colon } \\
\text { rectum }\end{array}$} & \multicolumn{2}{|c|}{$\begin{array}{c}\text { OPRT } \\
\mathrm{n} \mathrm{mol} / \mathrm{min} / \mathrm{mg} \text { protein }\end{array}$} & \multicolumn{2}{|c|}{$\begin{array}{c}\mathrm{DPD} \\
\mathrm{p} \mathrm{mol} / \mathrm{min} / \mathrm{mg} \text { protein }\end{array}$} & \multicolumn{2}{|c|}{$\begin{array}{c}\mathrm{TS} \\
\mathrm{p} \mathrm{mol} / \mathrm{min} / \mathrm{mg} \text { protein }\end{array}$} \\
\hline & & $\begin{array}{l}0.234 \pm 0.124 \\
0.252 \pm 0.188\end{array}$ & N.S. & $\begin{array}{l}44.2 \pm 28.3 \\
37.4 \pm 25.8\end{array}$ & N.S. & $\begin{array}{l}9.7 \pm 12.0 \\
6.3 \pm 6.2\end{array}$ & N.S. \\
\hline Histologic type & $\begin{array}{l}\text { well } \\
\text { mod } \\
\text { poor } \\
\text { muc }\end{array}$ & $\begin{array}{l}0.257 \pm 0.173 \\
0.239 \pm 0.153 \\
0.193 \pm 0.076 \\
0.229 \pm 0.086\end{array}$ & N.S. & $\begin{array}{l}38.2 \pm 26.0 \\
38.7 \pm 25.6 \\
63.1 \pm 27.6 \\
67.0 \pm 59.4\end{array}$ & $\mathrm{p}<0.05$ & $\begin{array}{l}9.4 \pm 12.0 \\
7.1 \pm 8.7 \\
8.4 \pm 6.3 \\
\quad 8.2\end{array}$ & N.S. \\
\hline $\begin{array}{l}\text { Lymph node } \\
\text { metastasis }\end{array}$ & $\begin{array}{l}\mathrm{n}(-) \\
\mathrm{n}(+)\end{array}$ & $\begin{array}{l}0.280 \pm 0.163 \\
0.216 \pm 0.145\end{array}$ & $\mathrm{p}<0.05$ & $\begin{array}{l}35.7 \pm 24.0 \\
44.9 \pm 28.9\end{array}$ & N.S. & $\begin{array}{l}8.8 \pm 12.0 \\
7.7 \pm 8.4\end{array}$ & N.S. \\
\hline $\begin{array}{l}\text { Depth of } \\
\text { tumor invasion }\end{array}$ & $\begin{array}{l}\mathrm{T} 2 \\
\mathrm{~T} 3 \\
\mathrm{~T} 4\end{array}$ & $\begin{array}{l}0.270 \pm 0.160 \\
0.237 \pm 0.138 \\
0.262 \pm 0.328\end{array}$ & N.S. & $\begin{array}{l}24.6 \pm 12.3 \\
43.8 \pm 28.1 \\
36.2 \pm 28.2\end{array}$ & N.S. & $\begin{array}{l}9.2 \pm 5.9 \\
8.1 \pm 10.7 \\
7.6 \pm 4.7\end{array}$ & N.S. \\
\hline Dukes stage & $\begin{array}{l}\text { B } \\
\text { C } \\
\text { D }\end{array}$ & $\begin{array}{l}0.258 \pm 0.126 \\
0.242 \pm 0.175 \\
0.218 \pm 0.162\end{array}$ & N.S. & $\begin{array}{l}37.4 \pm 24.7 \\
46.8 \pm 28.2 \\
37.8 \pm 29.0\end{array}$ & N.S. & $\begin{array}{l}9.1 \pm 12.6 \\
8.4 \pm 8.8 \\
6.4 \pm 7.0\end{array}$ & N.S. \\
\hline Vascular invasion & $\begin{array}{l}\mathrm{v}(-) \\
\mathrm{v}(+)\end{array}$ & $\begin{array}{l}0.238 \pm 0.133 \\
0.242 \pm 0.159\end{array}$ & N.S. & $\begin{array}{l}32.8 \pm 17.9 \\
42.5 \pm 28.3\end{array}$ & N.S. & $\begin{array}{l}8.1 \pm 3.8 \\
8.2 \pm 10.6\end{array}$ & N.S. \\
\hline Lyphatic invasion & $\begin{array}{l}\text { ly }(-) \\
\operatorname{ly}(+)\end{array}$ & $\begin{array}{l}0.219 \pm 0.120 \\
0.244 \pm 0.158\end{array}$ & N.S. & $\begin{array}{l}41.4 \pm 36.6 \\
41.2 \pm 26.5\end{array}$ & N.S. & $\begin{array}{l}5.2 \pm 2.9 \\
8.5 \pm 10.4\end{array}$ & N.S. \\
\hline
\end{tabular}

well: well-differentiated adenocarcinoma, mod: moderate differentiated adenocarcinoma, por: poorly differentiated adenocarcinoma, muc: mucinous adenocarcinoma. Values are reported as mean $\pm \mathrm{SD}$.

two different active forms: 5-fluorouridine triphosphate (FUTP) and FdUMP. These active forms induce anticancer effects by inhibiting RNA function and DNA synthesis, respectively. FdUMP inhibits DNA synthesis by binding with the nucleotide synthetic enzyme TS. Johnston et al. and Salonga et al. have reported that $5-\mathrm{FU}$ is more sensitive in cases of advanced colon cancer with low TS gene expression levels ${ }^{3,11}$. OPRT plays an extremely important role in cell proliferation. On the other hand, OPRT converts 5-FU to its active nucleotide, $\mathrm{FUMP}^{12}$. RNA function is inhibited when 5 -FU is phosphorylated by OPRT. DPD inactivates FU immediately.

Cases with high OPRT activity have a better prognosis than do cases with low OPRT activity ${ }^{13}$, and a positive correlation between OPRT activity and the antitumor effects of 5 -FU has been reported $^{2}$. Cases with high DPD activity have a poorer prognosis than do cases with low DPD activity,and DPD activity negatively correlates with 5-FU sensitivity ${ }^{14-16}$. TS is similar to DPD. In other words, OPRT, DPD, TS are not only prognostic factors for colorectal cancer but are also predictive factors of sensitivity to 5-FU. Therefore, the measurement of the activities of OPRT, TS, and $\mathrm{DPD}$ is useful for planning the treatment of colorectal cancer ${ }^{7,16}$. However an association of these enzyme activities with clinicopathological background factors of cancers has not been examined in detail.

This is the largest study that has measured OPRT, DPD, and TS activities in colorectal cancer. In this study, we found that OPRT activity is significantly lower in cases with lymph-node metastasis than in cases without lymph-node metastasis. Moreover, the DPD activity is higher in poorly differentiated adenocarcinoma than in welldifferentiated or moderately differentiated adenocarcinoma. In mucinous adenocarcinoma, OPRT activity tended to be high, and one of two cases showed high DPD activity. However, the number of cases of mucinous adenocarcinoma was small, and the differences did not reach the level of significance. Mucinous carcinoma tends to be hyposensitive to 5-FU, and low OPRT activity and high DPD activity are possible reasons.

The prognosis of colorectal cancer depends on 
pathological TMN staging and nodal status. In cases with lymphatic metastasis, the OPRT activity in the tumor may be lower. The prognosis of cases with lymph node metastasis may be poor because of low OPRT activity, indicating low sensitivity to 5 -FU, as well as lymph-node metastasis. Ochiai has reported that OPRT actitivity may be a prognostic factor and that patients with OPRT activity of at least 0.147 $\mathrm{nmol} / \mathrm{min} \mathrm{mg}$ have a better prognosis ${ }^{13}$. OPRT may also be a predictive factor for sensitivity to 5-FU; thus, when we perform chemotherapy, we should select agents other than 5-FU, such as irinotecan, or a combination therapy.

Similarly, the prognosis of poorly differentiated adenocarcinoma, in which the DPD activity is high in many cases, is poor because of low sensitivity to 5-FU. Thus, we should select combination therapy or $\mathrm{S}-1$, which is combined with a DPD inhibitor.

\section{Conclusion}

The response to 5-FU may be poor in patients with lymph-node metastasis, because of low OPRT activity, and in patients with poorly differentiated adenocarcinoma, because of high DPD activity. One reason for the poor prognosis of these cases is low sensitivity to 5 -FU.

\section{References}

1. Maughan TS, James RD, Kerr DJ, et al:: Comparison of survival, palliation, and quality of life with three chemotherapy regimens in metastatic colorectal cancer: multicentere randomized trial. Lancet 2002; 359: 1555-1563.

2. Fujii R, Seshimo A, Kameoka S: Relationships between the expression of thymidylate synthase, dihydropyrimidine dehydrogenase and orotate phosphoribosyl transferase and cell proliferative activity and 5-fluorouracil sensitivity in colorectal carcinoma. Int J Clin Oncol 2003; 8: 72-78.

3. Johnston PG, Lenz HJ, Leicman CG, et al.: Thymidylate synthase gene and protein expression correlate and are associated with response to 5fluorouracil in human colorectal and gastric tumors. Cancer Res 1995; 55: 1407-1412.

4. Edler D, Blomgren $\mathrm{H}$, Allegra CJ, et al.: Immunohistochemical determination of thymidylate synthase in colorectal cancer-methodological studies. Eur J Cancer 1997; 33: 2278-2281.
5. Ishikawa $\mathrm{Y}$, Kubota $\mathrm{T}$, Otani $\mathrm{Y}$, et al: Dihydropyrimidine dehydrogenase and messenger RNA levels in gastric cancer: possible predictor for sensitivity to 5-fluorouracil. Jpn J Cancer Res 2000; 91: 105-112.

6. Terashima M, Inorida T, Fujiwara H, et al:: Roles of thymidylate synthase and dihydropyrimidine dehydrogenase in tumor progression and sensitivity to 5 -fluorouracil in human gastric cancer. Anticancer Res 2002; 22: 761-768.

7. Isshi K, Sakuyama T, Gen T, et al.: Predicting 5-FU sensitivity using human colorectal cancer specimens; comparison of tumor dihydropyrimidine dehydrogenase and orotate phosphoribosyl transferase activities with in vitro chemosensitivity to 5-FU. Int J Clin Oncol 2002; 7: 335-342.

8. Shirasaka T, Shimamoto Y, Fukushima M: Inhibition by oxonic acid of gastrointestinal toxicity of 5fluorouracil without loss of its antitumor activity in rats. Cancer Res 1993; 53: 4004-4009.

9. Daiso RB, Beavers TL, Carpenter JT, et al.: Familial deficiency of dihydropyrimidine dehydrogenase. J Clin Invest 1988; 81: 47-51.

10. Spears CP, Shahinian AH, Moran RG, Heidelberger C, Corbett TH: In Vivo Kinetics of Thymidylate Synthetase Inhibition in 5-Fluorouracilsensitive and resistant Murine Colon Adenocarcinomas. Cancer Res 1982; 42: 450-456.

11. Salonga D, Danenberg KD, Jhonston M, et al.: Colorectal tumors responding to 5-fluorouracil have low gene expression levels of dihydropyrimidine dehydrogenase, thymidylate synthase and thymidine phosphorylase. Clin Cancer Res 2000; 6: 1322-1327.

12. Parker WB, Cheng YC: Metabolism and mechanism of action of 5-fluorouracil. Phamacol Ther 1990; 48: 381-395.

13. Ochiai T, Nishimura K, Noguchi H, et al.: Prognostic impact of orotate phosphoribosyl transferase among 5 -fluorouracil metabolic enzymes in resectable colorectal cancers treated by oral 5-fluorouracilbased adjuvant chemotherapy. Int J Cancer 2006; 118: 3084-3088.

14. Etienne MC, Cheradame S, Fischel JL, et al.: Response to fluorouracil therapy in cancer patients: the role of tumoral dihydropyrimidine dehydrogenase activity. J clin oncol 1995; 13: 16631670.

15. Fukushima M, Nomura H, Murakami Y, Shirasaka T, Aiba K: Estimation of pathway of 5-fluorouracil anabolism in human cancer cells in vitro and in vivo. Jpn J Cancer Chemother 1996; 23: 721-731.

16. Fujii R, Seshimo A, Kameoka S: Relationships between the expression of thymidylate synthase, dihydropyrimidine dehydrogenase, and orotate phosphoribosyltransferase and cell proliferative activity and 5-fluorouracil sensitivity in colorectal carcinoma. Int J Clin Oncol 2003; 8: 72-78.

(Received, July 9, 2007)

(Accepted, November 6, 2007) 